\title{
MBR 对污水中肠道模型病毒的去除效应
}

\author{
郑 祥 ${ }^{\oplus 0}$ 刘俊新 ${ }^{{ }^{*}}$
}

(1) 中国科学院生态环境研究中心, 北京 100085; (2) 中国人民大学环境学院, 北京 100872)

\begin{abstract}
摘要采用重力出流式膜生物反应器(MBR)对生活污水进行处理, 选择两种孔径的微滤膜考 察其对污水中 $\mathrm{T} 4$ 和 $\mathrm{f} 2$ 两种模型病毒的去除情况. 清水试验结果表明, 两种膜孔径组件对 T4 和 $\mathrm{f} 2$ 病毒的实际截留率远大于理论截留率; 两种膜组件对 $\mathrm{T} 4$ 病毒的截留均高于 $\mathrm{f} 2$ 病毒. 在 MBR 稳定运行状况下，两种不同孔径的膜组件对同一病毒的截留效果无显著差别：孔径为 $0.1 \mu \mathrm{m}$ 的 聚丙烯(PP)和孔径为 $0.22 \mu \mathrm{m}$ 的聚偏氟乙烯(PVDF) 对 T4 去除率均大于 $5.5 \mathrm{lg}$; 对 $\mathrm{f} 2$ 的去除率大 于 $3.0 \mathrm{lg}$. 其原因是膜表面的滤饼层、凝胶层在病毒的截留中起了重要的作用. 膜生物反应器对病 毒的去除由膜的截留、污泥絮体的吸附和生物灭活等作用共同完成. 进一步的研究发现: 活性污 泥系统对病毒去除率稳定在 $97 \%$ 以上，主要依靠生物灭活作用完成对病毒的去除.
\end{abstract}

\section{关键词膜生物反应器(MBR) 病毒 灭活 活性污泥}

\section{1 研究背景}

医院、畜禽养殖及屠宰场等分散点源的污水中含 有大量的病原微生物, 如果病原微生物在污水处理 过程中得不到高效去除就直接排放入自然水体或市 政管网，特别容易造成细菌、病毒的扩散并引起相应 的传染病. 我国通常使用大肠菌群作为控制污水中 病原微生物再生繁殖的卫生学指标. 与大肠菌群相 比, 病毒对消毒剂有更强的抵抗能力, 在环境中能存 活更长的时间 ${ }^{[1,2]}$. 由于病毒的检测复杂并且安全性 差, 因此长期以来病毒一直没有纳入污水的监测指 标体系. SARS 与近年来昺流感疫情的发生, 给这些 公共卫生敏感区域的污水排放提出了新的卫生学要 求. 2006 年开始执行的《医疗机构水污染物排放标准》 (GB 18466-2005)对医疗机构污水处理全过程的无害 化提出了新的要求, 增加了肠道病毒这一检测指标. 因此, 加强病毒在污水处理系统中的去除过程研究, 有效控制病毒在污水中的传播问题已经成为建立公
共卫生体系的迫切需要.

膜生物反应器(MBR)将污水生物处理与膜分离 相结合, 利用生化技术降解水中的有机物, 利用膜技 术过滤悬浮物和水溶性大分子物质，同时许多病原 微生物也得到有效的截留 ${ }^{[3 \sim 5]}$. 有研究表明：由于膜 的高效截留, MBR 出水中病原微生物的数量(总大肠 杆菌、粪大肠杆菌、粪链球菌、沙门氏菌等)能够达 到欧洲洗浴水管理委员会对排入游泳区废水的致病 菌所作的严格限制 ${ }^{[5 \sim 8]}$. 但长期以来 MBR 对病原微生 物的去除研究主要针对细菌, 而对病毒的去除研究 尚未引起足够的重视 ${ }^{[8 \sim 10]}$. 为了深入了解 MBR 系统 对病毒的去除过程及相关的影响因素, 本研究选择 两种不同类型的病毒一DNA 病毒与 RNA 病毒为研 究对象, 通过投加模型病毒 $\mathrm{T} 4$ 与 $\mathrm{f} 2$ 进行批量与连续 运行试验, 研究不同的膜分离系统对病毒的截留效 果以及病毒在生物处理系统中的去除过程.

大肠杆菌噬菌体 $\mathrm{T} 4$ 的尺寸和结构与命流感病 毒、SARS 冠状病毒、人类免疫缺陷病毒(HIV)非常

收稿日期: 2006-09-20; 接受日期: 2006-10-26

国家自然科学基金(批准号: 50538090)、中国科学院生态环境研究中心环境水质学国家重点实验室开放基金(批准号: 200601)和中国人民大学研究 基金(批准号: 30206101.201.301)资助项目

*联系人, E-mail: jxliu@rcees.ac.cn 
接近; 而噬菌体 $\mathrm{f} 2$ 的尺寸和结构与肠道病毒非常接 近(见表 1). 同时噬菌体 $\mathrm{T} 4$ 与 $\mathrm{f} 2$ 对人类健康的负面 影响可基本忽略，不会在水环境中增殖并广泛分布 在废水和被生活污水污染的其它水体中，能够代表 污水处理过程中实际发生的病毒去除机制 ${ }^{[11 ~ 13]}$. 因 此本试验中以噬菌体 $\mathrm{T} 4$ 与 $\mathrm{f} 2$ 作为模型病毒, 采用不 同孔径的膜组件对噬菌体的去除效果及机理进行系 统的研究, 以便为膜分离技术在水处理中的推广应 用提供有益的借鉴.

表 1 不同病毒的大小与形状

\begin{tabular}{|c|c|c|}
\hline 病毒 & 直径 & 形状 \\
\hline 禽流感病毒 & $80 \sim 120 \mathrm{~nm}$; ssRNA & $\begin{array}{l}\text { 球形, 表面有 } \\
10 \sim 12 \mathrm{~nm} \text { 的钉状物 } \\
\text { 覆盖 }\end{array}$ \\
\hline SARS 冠状病毒 & $80 \sim 250 \mathrm{~nm}$ & $\begin{array}{l}\text { 球形, 表面覆盖着 } \\
\text { 直径为 } 10 \sim 20 \mathrm{~nm} \text { 的 } \\
\text { 刺突 }\end{array}$ \\
\hline 人类免疫缺陷病毒 $(\mathrm{HIV})$ & $90 \sim 140 \mathrm{~nm}$; ssRNA & 圆形或椭圆形 \\
\hline $\mathrm{T} 4$ 噬菌体 & $\begin{array}{l}\text { 头部 } 65 \mathrm{~nm} \times 95 \mathrm{~nm} \text {, } \\
\text { 尾部 } 25 \mathrm{~nm} \times 110 \mathrm{~nm} \text {, } \\
\text { dsDNA }\end{array}$ & $\begin{array}{l}\text { 复合对称结构: 头 } \\
\text { 部呈二十面体对称, } \\
\text { 尾部呈螺旋对称 }\end{array}$ \\
\hline 肠道病毒 & $17 \sim 28 \mathrm{~nm}, \mathrm{ssRNA}$ & 正二十面体 \\
\hline $\mathrm{f} 2$ 噬菌体 & $24 \sim 26 \mathrm{~nm}$, ssRNA & 正二十面体 \\
\hline
\end{tabular}

\section{2 实验条件与方法}

\section{1 实验系统}

本研究采用重力出流式 MBR 对生活污水进行了 实验研究, 它利用生物反应器内液位水头 $(8.5 \mathrm{kPa})$ 的 重力驱动连续出水. 实验系统如图 1 所示, 主要由气 升式好氧反应器、膜组件及曝气单元组成. 好氧反应 器容积为 $12 \mathrm{~L}$, 曝气量为 $0.4 \sim 1.0 \mathrm{~m}^{3} / \mathrm{h}$. 为了考察膜 孔径对截留病毒的影响, 选择了孔径为 $0.1 \mu \mathrm{m}$ 的聚 丙烯 $(\mathrm{PP})$ 和孔径为 $0.22 \mu \mathrm{m}$ 的聚偏氟乙烯 $(\mathrm{PVDF})$ 两种 中空纤维微滤膜制成膜组件. 实验废水取自北京某 居民区的污水井.

\section{2 病毒的培养}

噬菌体及其宿主：噬菌体 $\mathrm{T} 4$ 及其宿主菌 E. coli B 购自中国科学院武汉病毒所; 噬菌体 $\mathrm{f} 2$ 及其宿主 $E$. coli 285 购自军事医学科学院卫生学环境医学研究所.

噬菌体 $\mathrm{T} 4 / \mathrm{f} 2$ 的制备: 大肠杆菌 E.coli B/E.coli $285 \rightarrow$ 接入 $\mathrm{LB}$ 培养液 $37^{\circ} \mathrm{C} 、 150 \mathrm{r} / \mathrm{min}$ 条件下培养过 夜 $\rightarrow$ 接入噬菌体 $\mathrm{T} 4 / \mathrm{f} 2 \rightarrow$ 裂解透明液 $\rightarrow$ 加入幼龄大肠

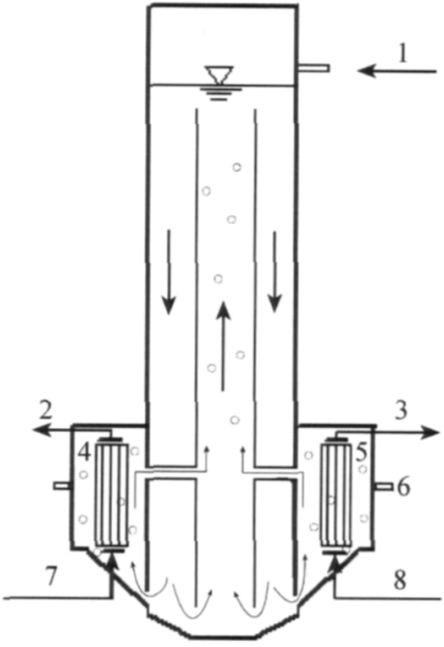

图 1 实验系统示意图

1 , 进水口; 2,3 出水口; 4, 微滤膜组件 I $(0.22 \mu \mathrm{m}) ; 5$, 微滤膜组件 II $(0.1 \mu \mathrm{m}) ; 6$, 排泥口; 7,8, 进气口

杆菌培养物 $\rightarrow$ 调节 $\mathrm{pH}$ 为中性 $\rightarrow 12000 \mathrm{r} / \mathrm{min}$ 高速离心 $\rightarrow 0.22 \mu \mathrm{m}$ 微孔滤膜过滤. 滤过液即为噬菌体 $\mathrm{T} 4 / \mathrm{f} 2$ 浓缩液. 浓缩液密封后置于 $4^{\circ} \mathrm{C}$ 冰箱保存备用.

噬菌体 $\mathrm{T} 4$ 与 $\mathrm{f} 2$ 的效价测定均采用双层琼脂平板 法. 首先将待测噬菌体悬浮液进行 10 倍系列稀释, 然后将上层培养基 $(5 \mathrm{~mL})$ 、宿主菌 $(0.2 \mathrm{~mL})$ 与待检测 的噬菌体样品 $(1 \mathrm{~mL})$ 混合均匀, 倒入已凝固的底层培 养基 $(20 \mathrm{~mL})$ 上摇动使之铺匀倾倒后，置于 $37^{\circ} \mathrm{C}$ 的生 化培养箱中培养, 4 6 h 计数空斑单位(PFU), 取噬斑 数在 30 300 个之间的平皿计算效价，一个 PFU 计为 一个具感染活性的病毒.

大肠杆菌噬菌体 $\mathrm{T} 4$ 应用原子力显微镜(NanoScope III a Multimode, Digital Instruments, Santa Barbara, CA, USA), 在室温和大气环境条件下采用轻敲 模式进行成像观测. $\mathrm{T} 4$ 的平均尺寸为 $107.9 \pm 12.9 \mathrm{~nm}$. PP 与 PVDF 膜的 SEM 照片采用FEI QUANTA 200 扫 描电子显微镜(Scanning Electron Microscope, Holand) 进行拍摄.

\section{3 膜的分离性能}

在本实验中，用表观去除率表征 MBR 系统对病 毒的去除效果，用本征截留率表征膜系统对病毒的 截留性能，它们的表达式如下.

表观去除率: $\mathrm{LRV}_{1}=\lg c_{\text {in }} / c_{\text {out, }}$

本征截留率: $\mathrm{LRV}_{2}=\lg c_{\text {super }} / c_{\text {out, }}$ 式中 $c_{\text {in }}, c_{\text {super }}, c_{\text {out }}$ 分别为进水、上层清液(污泥混合液 
以 $4000 \mathrm{r} / \mathrm{min}$ 离心 $10 \mathrm{~min}$ 所得)和膜出水中的病毒浓 度.

\section{4 污泥中噬菌体的提取}

污泥中噬菌体的提取采用 EDTA-G1y 洗脱法: 取活性污泥混合液 $50 \mathrm{~mL}$ ，以 $4000 \mathrm{r} / \mathrm{min}$ 离心 $10 \mathrm{~min}$, 去除上层清液. 向剩余污泥中加入 EDTA-G1y 缓冲 液(0.05 mol/L EDTA, $0.25 \mathrm{~mol} / \mathrm{L} \mathrm{Gly}, \mathrm{pH}=9.5)$ 至 50 $\mathrm{mL}$. 充分搅拌后, 以 $5000 \mathrm{r} / \mathrm{min}$ 离心 $15 \mathrm{~min}$ 后取上层 清液，将上清液 $\mathrm{pH}$ 调至 7.2.

\section{3 实验结果与讨论}

\section{1 膜对模型病毒的截留(单组分体系)}

首先在单一组分的溶液环境中, 采用新膜进行 病毒的截留研究. 膜分离的对象为投加一定量模型 病毒的清水，通过膜分离前后病毒浓度的变化来了 解膜对病毒的截留性能(见表 2). 研究表明: 采用孔 径为 $0.22 \mu \mathrm{m}$ 的 PVDF 膜对模型病毒 T4 的截留量达 $2.1 \lg$ (膜分离前后微生物浓度比值的对数, 即 $\lg c_{\text {分离前 }}$ $c$ 分离后 $=2.1$ ), 采用孔径为 $0.1 \mu \mathrm{m}$ 的 PP 膜的截留量则 高达 $5.8 \mathrm{lg}$. 而对于个体更小的模型病毒 $\mathrm{f} 2, \mathrm{PVDF}$ 膜 与 PP 膜对 $\mathrm{f} 2$ 的截留能力的差距则明显缩小: PVDF 膜对 f2 截留量达 $0.3 \mathrm{lg}$; PP 膜的截留量达到 $0.5 \mathrm{lg}$.

微滤是基于篮分原理即膜孔尺寸的大小对不同 大小的物质进行分离的过程. 因此, 膜孔径和被分离 颗粒物质的粒径是影响膜截留率的主要因素 ${ }^{[14 ~ 16]}$. 膜对颗粒物质的截留效果通常可以通过下式进行估 算 ${ }^{[17]}$ :

$$
R=[\lambda(2-\lambda)]^{2},
$$

其中 $\lambda$ 为被分离颗粒物质半径 $r_{\mathrm{s}}$ 与膜孔半径 $r_{\mathrm{p}}$ 之比

模型病毒 $\mathrm{f} 2$ 的直径只有 PVDF 膜和 PP 膜孔径的 $1 / 8 \sim 1 / 4$, 因此 PVDF 与 PP 膜对 $\mathrm{f} 2$ 只有 4.6\%, 19.1\% 的理论截留率. 而在实际的膜分离过程中, PVDF 膜
和 PP 膜对 f 2 分别达到 $48.6 \%$ 与 $70.2 \%$ 的截留率. 膜 对病毒的实际截留率远大于理论截留率，其可能的 原因主要有以下两点：(1) 理论公式是按均匀粒径和 孔径计算，但实际上病毒和膜孔径都不是均匀的. 通 常所指的膜孔径是膜的平均孔径，实际上膜孔径的 分布并不完全均匀，膜在成膜过程中，表面形成的孔 径大小并不一致，而是存在一个孔径分布范围. 因此 即使是平均孔径相同的几种膜对同一个被分离物也 可能具有不同的截留率. (2) 病毒有可能相互黏附在 一起，其实际粒径大于单体病毒. 病毒粒子因其特殊 的表面结构(病毒的外表面均为蛋白构成)引起的表面 作用很容易使它们通过吸附而团聚在一起，形成带 有若干弱连接界面的尺寸较大的团聚体. 病毒离子 间相互团聚作用是蛋白质大分子间氢键和静电作用 产生的吸附. 图 2 为不同病毒浓度下原子力显微镜对 T4 的观测结果，也初步证实了这两种推测：病毒的 大小并不是完全均一; 并且在较高的浓度下, 病毒粒 子很容易通过吸附形成尺寸较大的团聚体.

另外，膜的径向断面为非对称、多层相叠的笁网 状结构有利于膜对病毒的截留. 膜对病毒的分离效 果与膜自身的物化性质(如孔径、孔径分布、孔隙率、 膜材料的亲水/疏水性和电荷性等)密切相关. 从图 3 扫描电子显微镜照片可以看出, PVDF 膜与 PP 膜都是 多层相叠的具有不规则孔型的重叠耖网状结构. 虽 然膜孔径大大高于 $\mathrm{f} 2$ 噬菌体的平均尺寸，但是由于 不规则的膜孔形态以及上下网孔的重叠结构，使其 通道的有效直径大为缩小，因此对病毒具有很高的 截留能力.

\subsection{MBR 系统对模型病毒的去除效果(多组分体 系)}

膜在分离活性污泥的过程中，污泥能够迅速 在膜表面吸附和沉积形成滤饼层; 随着运行时间

表 2 膜对模型病毒的截留能力

\begin{tabular}{|c|c|c|c|c|}
\hline \multirow{2}{*}{ 截流性能 } & \multicolumn{2}{|c|}{$\mathrm{T} 4$} & \multicolumn{2}{|c|}{$\mathrm{f} 2$} \\
\hline & PVDF $(0.22 \mu \mathrm{m})$ & $\mathrm{PP}(0.1 \mu \mathrm{m})$ & $\operatorname{PVDF}(0.22 \mu \mathrm{m})$ & $\mathrm{PP}(0.1 \mu \mathrm{m})$ \\
\hline 分离前浓度/lg PFU $\cdot \mathrm{mL}^{-1}$ & 5.8 & 5.8 & 5.0 & 5.0 \\
\hline 分离后浓度/lg PFU $\cdot \mathrm{mL}^{-1}$ & 3.7 & 0 & 4.7 & 4.5 \\
\hline 截留量/lg PFU·mL mL $^{-1}$ & 2.1 & 5.8 & 0.3 & 0.5 \\
\hline$\lambda=r_{\mathrm{s}} / r_{\mathrm{p}}$ & $0.49 \pm 0.06$ & $1.07 \pm 0.13$ & 0.11 & 0.25 \\
\hline 理论截留率a)/\% & $54.5 \pm 8.5$ & $99.8 \pm 0.2$ & 4.6 & 19.1 \\
\hline 实际截留率/\% & 99.2 & 99.9998 & 48.6 & 70.2 \\
\hline
\end{tabular}

a) 理论截留率是根据篮分原理(式(1))计算所得数值 

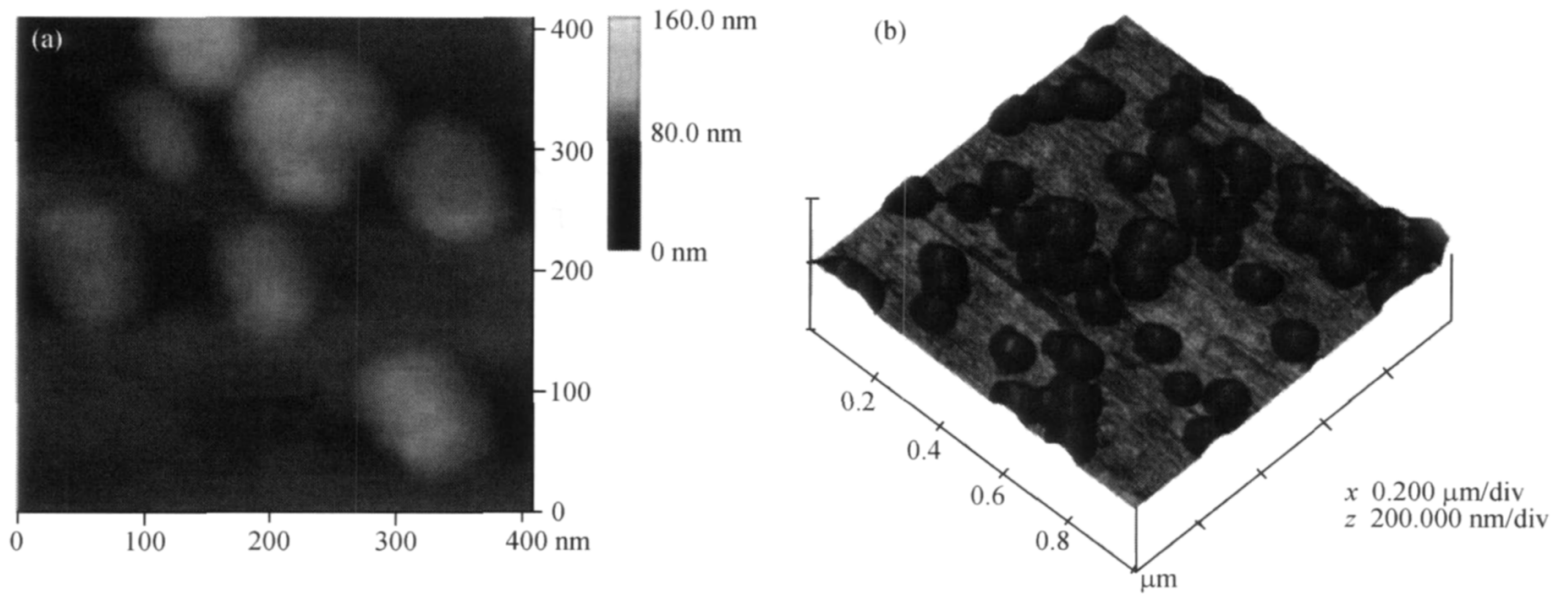

图 $2 \mathrm{~T} 4$ 的 AFM 照片

(a) 低浓度; (b) 高浓度
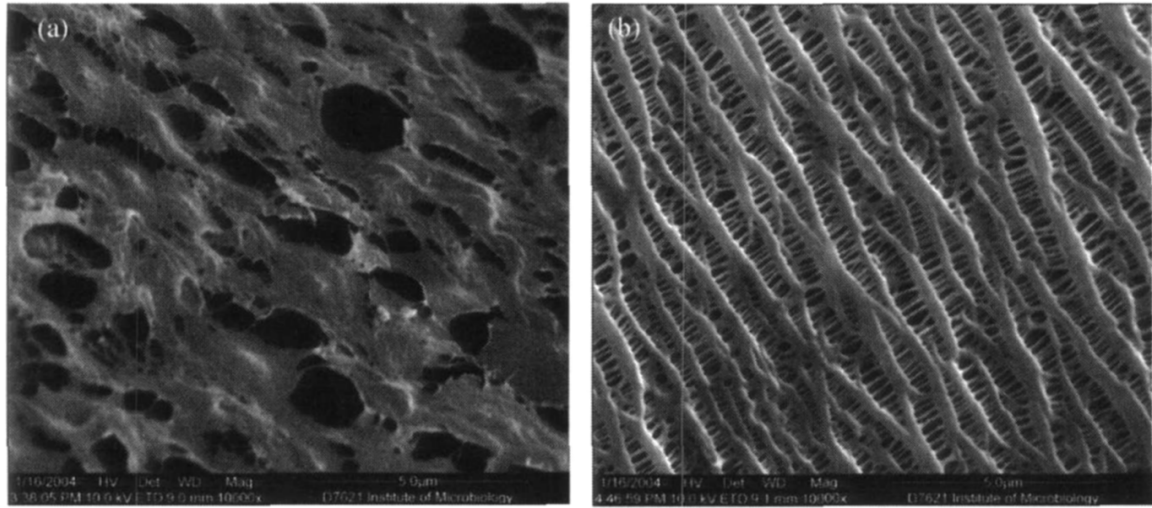

图 3 新膜的 SEM 照片

(a) PVDF 膜 $(\times 10000$ 倍 $)$; (b) PP 膜 $(\times 10000$ 倍 $)$

的延长，生物反应器中微生物代谢产生的粘性多 糖类物质和一些蛋白质分子等逐渐在膜表面形成 凝胶层，膜的分离特性会因滤饼层以及凝胶层的 形成而有所改变. 图 4 为连续运行试验中 $0.22 \mu \mathrm{m}$ 孔径膜的 MBR 系统对 T4 的去除效果. 在投加病毒后 的第 $12 \mathrm{~h}$, 出水中可检测出 $10 \mathrm{PFU} / \mathrm{mL}$ 的 T4, 但随着 运行时间的延长，膜出水中 $\mathrm{T} 4$ 的数量呈显著的下降 趋势. 在随后 $20 \mathrm{~d}$ 的连续运行过程中，仅有 $50 \%$ 的出 水样品中检测出 1 2 PFU/mL 的 T4. 在本研究中同时 考察了 $0.1 \mu \mathrm{m}$ 孔径的 PP 膜对 T4 的截留效果，只有 $20 \%$ 的出水样品中检测出 $1 \mathrm{PFU} / \mathrm{mL}$ 的噬菌体. 在连 续运行过程中, PVDF 膜和 PP 膜对噬菌体 T4 的截留 效果并无显著差别，两种孔径的膜对病毒的去除都 大于 $5.5 \mathrm{lg}$.

图 5 为连续运行试验中 MBR 系统对 $\mathrm{f} 2$ 的去除效

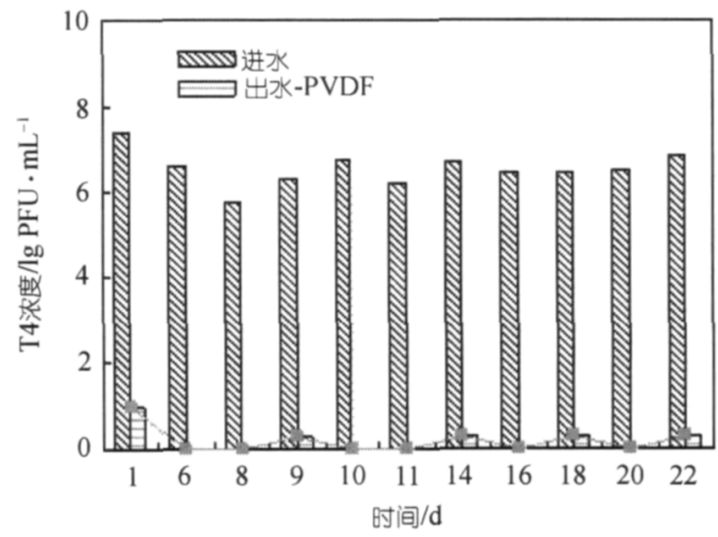

图 4 MBR(PVDF 膜)对 T4 的截留

果. PVDF 膜与 PP 膜在清水系统中对噬菌体 $\mathrm{f} 2$ 的截 留分别为 $48.6 \%(0.3 \mathrm{lg})$ 与 70.2\%(0.5 lg). 当活性污泥 系统运行 $18 \mathrm{~h}$ 后, PVDF 膜与 PP 膜的膜阻力迅速从 


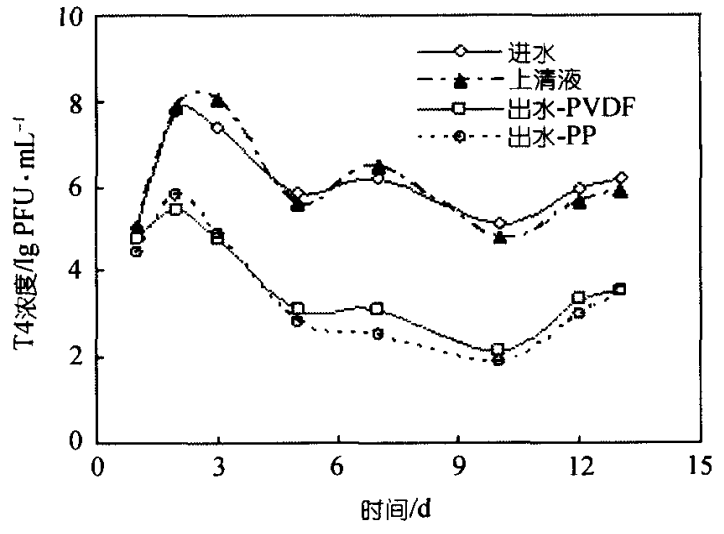

图 5 PVDF 和 PP 膜对 $\mathrm{f} 2$ 的截留

分离活性污泥前的 $5.2 \times 10^{11}, 2.9 \times 10^{12} \mathrm{~m}^{-1}$ 上升到 $1.9 \times 10^{12}, 6.2 \times 10^{12} \mathrm{~m}^{-1}$, PVDF 膜对噬菌体 $\mathrm{f} 2$ 的截留 率上升到 $99.63 \%(2.4 \mathrm{lg}), \mathrm{PP}$ 膜的截留率为 $99.14 \%$ $(2.1 \mathrm{lg})$. 这表明活性污泥已经在两种膜表面吸附 并沉积形成相对稳定的滤饼层, 膜对病毒的截留 性能随着滤饼层的快速形成在短时间内迅速提高. 随 着运行时间的延长, PVDF 膜与 PP 膜对 $\mathrm{f} 2$ 的截留量 进一步提高并稳定在 3 4 $\mathrm{lg}$ 的水平. 当 MBR 稳定运 行到 $6 \mathrm{~d}$ 后, PVDF 膜对 $\mathrm{f} 2$ 的截留率为 $99.95 \%$; PP 膜对 f2 的截留率为 $99.99 \%$, 远高于清水试验或 采用新膜的截留率.

\section{3 动态膜对病毒截留的贡献}

在清水系统中, PVDF 膜对 T4 和 $\mathrm{f} 2$ 只有 $2.1 \mathrm{lg}$ 与 $0.3 \mathrm{lg}$ 的截留. 而在 MBR 系统中, 系统对 $\mathrm{T} 4$ 和 $\mathrm{f} 2$
病毒分别大于 $5.5 \mathrm{lg}$ 与 $3.0 \mathrm{lg}$. 这说明 PVDF 膜在分离 活性污泥的过程中，膜表面形成的动态层一一滤饼 层与凝胶层在病毒的截留中起了重要的作用. 为了 区分凝胶层与滤饼层对 $\mathrm{T} 4$ 截留的相对贡献，在 MBR 系统连续运行结束后, 采用清水、 $\mathrm{NaOH}$ 与 $\mathrm{NaOCl}$ 的 混合液对膜组件分别进行物理冲洗和化学清洗. 清 水的物理冲洗用于去除膜表面的污泥滤饼层，排除 滤饼层对病毒截留的贡献; 化学清洗用于去除以多 糖和蛋白类物质为主的凝胶层对病毒去除的贡献. 清水的物理冲洗结束后，用投加了 $\mathrm{T} 4$ 的清水进行病 毒的膜分离试验, 结果从 PVDF 膜的出水中检测出 $2.7 \mathrm{lg}$ 的噬菌体. PVDF 膜对 $\mathrm{T} 4$ 的截留从物理清洗前 的 $6.1 \mathrm{lg}$ 降到清洗后的 $2.8 \mathrm{lg}$, 物理清洗前后截留量 的差值即为滤饼层对病毒截留的贡献. 这一结果表 明，PVDF 膜表面的滤饼层对 T4 的截留高达 3.3 个 数量级.

膜经化学清洗后，同样在清水体系中投加 T4 进 行病毒的截留实验. 实验结果表明, $0.22 \mu \mathrm{m}$ 孔径膜 出水中病毒的浓度从化学清洗前的 $2.7 \mathrm{lg}$ 上升到 $3.4 \sim 4.2 \mathrm{lg}$, 膜对病毒的截留量降到 $2.0 \mathrm{lg}$, 该截留量 即为膜自身对病毒截留的贡献. 从表 3 可以看出, 对 于孔径为 $0.22 \mu \mathrm{m}$ 的膜组件, 对 $\mathrm{T} 4$ 截留有重要的贡 献大小为：滤饼层 $>$ 膜自身 $>$ 凝胶层. 而对于 $0.1 \mu \mathrm{m}$ 孔径的膜组件，滤饼层与凝胶层的去除没有影响膜 对病毒的截留, 这说明孔径为 $0.1 \mu \mathrm{m}$ 的膜组件主要 依靠自身较小的膜孔径完成对 T4 噬菌体的截留(表 $4)$.

表 3 不同体系中 PVDF 膜对 T4 的截留 ${ }^{\text {a) }}$

\begin{tabular}{|c|c|c|c|}
\hline 分离对象 & 活性污泥 & 清水(清水冲洗后) & 清水(化学清洗后) \\
\hline$R_{\mathrm{t}}$ & $R_{\mathrm{m}}+R_{\mathrm{g}}+R_{\mathrm{c}}$ & $R_{\mathrm{m}}+R_{\mathrm{g}}$ & $R_{\mathrm{m}}$ \\
\hline$R_{\mathrm{t}}$ & $6.4 \times 10^{-12}$ & $3.5 \times 10^{-12}$ & $1.5 \times 10^{-12}$ \\
\hline 分离前浓度 $/ \mathrm{g} \mathrm{PFU} \cdot \mathrm{mL}^{-1}$ & $6.3 \pm 0.1$ & $5.5 \pm 0.4$ & $5.8 \pm 0.0$ \\
\hline 分离后浓度 $/ \mathrm{g} \mathrm{PFU} \cdot \mathrm{mL}^{-1}$ & $0.2 \pm 0.2$ & $2.7 \pm 0.0$ & $3.8 \pm 0.6$ \\
\hline 截留量/lg PFU·mL ${ }^{-1}$ & $6.1 \pm 0.2$ & $2.8 \pm 0.4$ & $2.0 \pm 0.6$ \\
\hline
\end{tabular}

a) $R_{\mathrm{t}}, R_{\mathrm{m}}, R_{\mathrm{g}}$ 和 $R_{\mathrm{c}}$ 分别为膜的总阻力、膜自身阻力、凝胶层阻力和滤饼层阻力

表 4 不同体系中 PP 膜对 T4 的截留 ${ }^{\mathrm{a})}$

\begin{tabular}{|c|c|c|c|}
\hline 分离对象 & 活性污泥 & 清水(清水冲洗后) & 清水(化学清洗后) \\
\hline$R_{\mathrm{t}}$ & $R_{\mathrm{m}}+R_{\mathrm{g}}+R_{\mathrm{c}}$ & $R_{\mathrm{m}}+R_{\mathrm{g}}$ & $R_{\mathrm{m}}$ \\
\hline$R_{\mathrm{t}}$ & $21.2 \times 10^{-12}$ & $9.1 \times 10^{-12}$ & $5.1 \times 10^{-12}$ \\
\hline 分离前浓度/lg PFU · mL $L^{-1}$ & $6.3 \pm 0.1$ & $5.5 \pm 0.4$ & $5.8 \pm 0.0$ \\
\hline 分离后浓度/lg PFU $\cdot \mathrm{mL}^{-1}$ & $0.0 \pm 0.0$ & $0.0 \pm 0.0$ & $0.3 \pm 0.0$ \\
\hline 截留量/lg PFU·mL ${ }^{-1}$ & $6.3 \pm 0.1$ & $5.5 \pm 0.4$ & $5.5 \pm 0.6$ \\
\hline
\end{tabular}

a) $R_{\mathrm{t}}, R_{\mathrm{m}}, R_{\mathrm{g}}$ 和 $R_{\mathrm{c}}$ 分别为膜的总阻力、膜自身阻力、凝胶层阻力和滤饼层阻力 


\section{4 病毒在生物系统的去除过程}

污水生物处理系统对病毒的去除通常由活性污 泥对病毒的物理吸附以及微生物对病毒的生物灭活 作用共同完成. 大部分的研究者认为: 生物处理系统 对病毒的去除主要是通过污泥的吸附作用完成，病 毒在污水生物处理的去除在很大程度上仅是从液相 (污水)到固相(污泥)的迁移过程, 即以病毒在污泥中 的浓缩而告终, 并不是真正意义上的灭活 ${ }^{[14 ~ 16]}$. 因为 灭活意味着病毒壳体或核酸遭到破坏，病毒从液相 到固相的迁移没有破坏病毒的结构，吸附在污泥表 面的病毒并没有失去感染宿主细胞的能力. 在 MBR 系统中，由于高浓度病毒被膜截留在生物反应器，如 果被截留的病毒没有在生物系统中得到有效灭活, 生物反应器中的病毒浓度将逐步提高. 而在系统连 续运行过程中，污泥混合液和上清液中的 $\mathrm{T} 4$ 与 $\mathrm{f} 2$ 浓度与进水浓度基本维持在同一个数量级，说明病 毒在 MBR 系统内得到有效的灭活.

在 MBR 系统中, 膜对病毒的截留仅仅影响病毒 在生物反应器系统内与膜出水这两个子系统中的比 例分配，并不能完成对病毒的灭活. 为了更直观了解 活性污泥系统对噬菌体 T4 的灭活过程，本研究考察 了含 $\mathrm{T} 4$ 污水流经活性污泥系统时 $\mathrm{T} 4$ 的去除效果 和去除方式. 由于不存在膜的截留，在这样一个开 放的体系内, 活性污泥系统进出水病毒浓度的差值 可以直观代表生物系统对病毒的去除效果.图 6 为活性污泥系统进出水病毒浓度及去除率. 在 $28 \mathrm{~d}$ 的连续运行过程中，当进水病毒浓度在 $3.3 \sim 4.8 \mathrm{lg}$ 的范围时，系统对病毒浓度去除率稳定在 97\% $99 \%$.

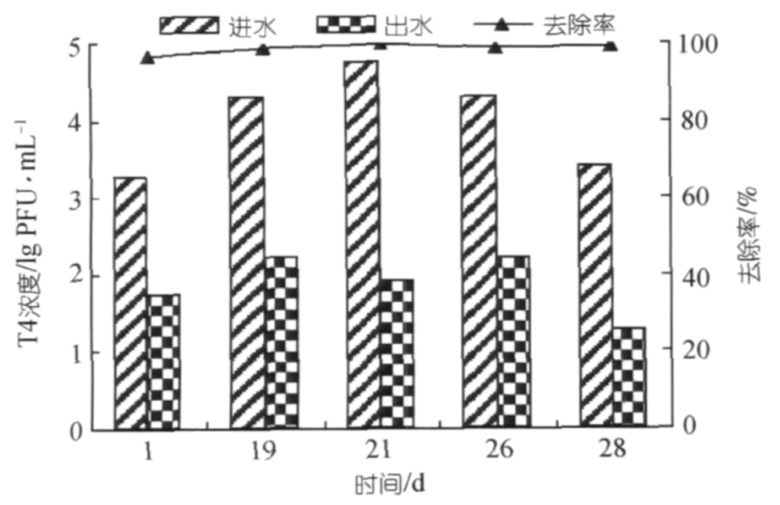

图 6 活性污泥系统中 $\mathrm{T} 4$ 的去除效果
水环境中的病毒一般都能与水中悬浮的固体 物结合，这些固体物经过篮滤和沉降作用得以截 留在淤泥中. 为了区分污泥的物理吸附与生物灭 活作用在病毒总去除率中的作用，本研究采用 EDTA-G1y 洗脱法测定污泥中吸附的模型病毒 T4. 在活性污泥系统运行的第一天, 含 T4 污水流经系统 $15 \mathrm{~h}$ 后取样检测，系统对病毒的去除达到 $96.8 \%$, 其 中生物灭活对病毒去除的贡献为 $75.0 \%$, 污泥吸 附的贡献为 $21.8 \%$. 随着时间的延长, 污泥吸附对 病毒去除的贡献呈显著的下降趋势，如图 7 所示. 在随后运行过程中，生物灭活对病毒去除的贡献 提高到 $97.2 \%$ 98.5\%，并稳定在这一水平，污泥 吸附的贡献相应地降低到 $0.8 \%$ 2.0\%。这说明活 性污泥系统主要依靠生物灭活作用完成对病毒的 去除。

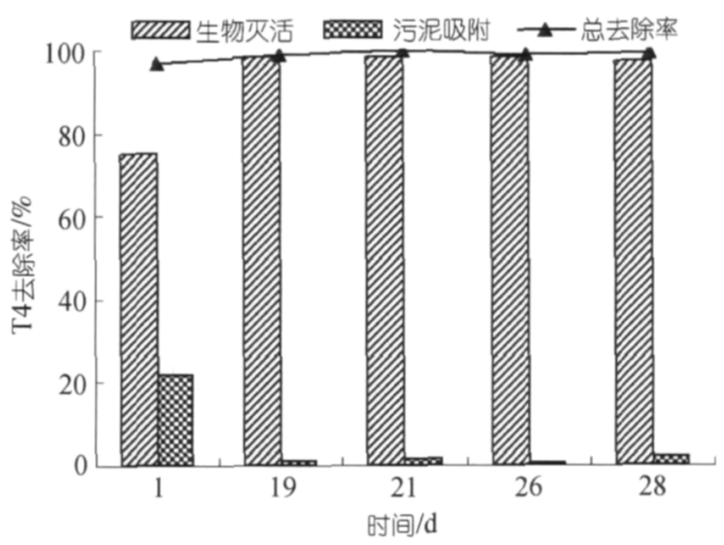

图 7 活性污泥系统中 $\mathrm{T} 4$ 的去除方式

\section{4 结论}

（1）清水实验结果表明，膜对病毒具有显著的截 留作用，且截留效果与膜孔径有关;

(2) 在 MBR 稳定运行状况下, 对病毒的截留率 高达 99.99\%以上. 测试结果表明，两种孔径膜对 T4 与 $\mathrm{f} 2$ 的截留效果无显著差别, 其原因是膜表面的滤 饼层、凝胶层在病毒的截留中起了重要的作用;

(3) 在活性污泥系统中, 对病毒的去除主要依靠 生物灭活作用完成，去除率稳定在 $97 \%$ 以上. 污泥对 病毒吸附去除的贡献在初期比较大，随着时间的延 长，对病毒去除的贡献呈下降趋势.

致谢中国地质大学水资源与环境学院张凯同学, 中国人民大学环境学院叶磊、何明、姜大千同学参与 部分实验工作，特此感谢. 


\section{参考 文 献}

1 魏东斌, 胡洪营, 王丽莎. 污水再生回用的水质安全指标体系. 中国给水排水, 2004, 20(1): 36-39

2 仇付国, 王晓昌. 城市回用污水中病毒对人体健康风险的评价. 环境与健康杂志, 2003, 20(4): 197-199

3 Zheng X, Lü W Z, Yang M, Liu J X. Evaluation of virus removal in MBR using coliphages T4. Chin Sci Bull, 2005, 50(9): 862-867

4 Lv W Z, Zheng X, Yang M, Liu J X. Removal efficiency of viruses in simulated hospital wastewater by using a submerged membrane bioreactor. Process Biochem, 2006, 41: 299-304

5 Gunder B, Krauth K. Replacement of secondary clarification by membrane separation-results with plate and hollow fibre modules. Wat Sci Tech, 1998, 38(4-5): 383-393

6 Steven W T, Simon J J, Bob M. Reduction of faecal coliform bacteria in sewage effluents using a microporous polymeric membrane. Water Res, 1998, 32(5): 1417-1422

7 Krauth K, Staab K F. Pressurized bioreactor with membrane separation for wastewater treatment, Water Res, 1993, 27(3): 405-411

8 Zheng X, Liu J X. Mechanism investigation of virus removal in a Membrane Bioreactor. Wat Sci Tech, 2006, 6(6): 51-59
9 Ueda T, Horan N J. Fate of indigenous bacteriophage in a membrane bioreactor. Water Res, 2000, 34 (7): 2151-2159

10 Shang C, Wong H M, Chen G H. Bacteriophage MS-2 removal by submerged membrane bioreactor. Water Res, 2005, 39: 42114219

11 Britton G. Introduction to Environmental Virology. New York: John Wiley \& Sons, Inc, 1980. 300-317

12 Berg G. Viral Pollution of the Environment. Boca Raton: CRC Press, Inc, 1983. 141-145

13 李梅, 胡洪营. 噬菌体作为水中病毒指示物的研究进展. 中国 给水排水, 2005, 21(2): 23-26

14 Urase T, Yamamoto K, Shinichiro O. Effect of pore size distribution of ultrafiltration membranes on virus rejection in crossflow conditions. Wat Sci Tech, 1994, 30(9): 199-208

15 Madaeni S S. The application of membrane technology for water disinfection. Water Res, 1999, 33(2): 301-308

16 Herath G, Yamamoto K, Urase T. Mechanism of bacterial and virus transport through microfiltration membranes. Wat Sci Tech, 1998, 38(4-5): 489-496

17 时钧, 袁权, 高从堦. 膜技术手册. 北京: 化学工业出版社, 2001.337-339 